\title{
Variation of parasitism patterns in bats during hibernation: the effect of host species, resources, health status, and hibernation period
}

\author{
Tomasz Postawa $^{1} \cdot$ Zoltan Nagy $^{2}$
}

Received: 1 March 2016 / Accepted: 17 May 2016 / Published online: 30 May 2016

(C) The Author(s) 2016. This article is published with open access at Springerlink.com

\begin{abstract}
During critical periods of food shortage or variable climatic conditions, the choice of an appropriate host can increase the survival and reproductive performance of parasites. In turn, one of the unique adaptations to periodical food shortages is hibernation, which is often found among insectivorous bat species in the temperate zone. While hibernating, bats are completely defenseless against both predators and ectoparasites, their immune and endocrine systems are diminished, and survival is dependent on the accumulated fat reserves. Differences in the health status or in the rate of consumption of the resources might also explain species-specific differences in ectoparasite abundance, especially between closely related host species, such as the greater mouse-eared bat (Myotis myotis) and the lesser mouse-eared bat (M. blythii) during hibernation. In the present study, the abundance of two ecologically distinct (summer and winter) types of ectoparasites was examined in terms of its influence on the body condition and hemoglobin content of the two host species. The effects of demographic factors, such as host sex and age, were also investigated. Despite a similar pattern of deteriorating body condition and hemoglobin concentration, M. myotis was more parasitized than was M. blythii. The marked decrease in hemoglobin content in first-year females of both host species correlated with the highest parasite load and indicated a risk of anemia. At the intraspecific level, ectoparasite abundance was not correlated with body condition
\end{abstract}

Tomasz Postawa

tpostawa@gmail.com

1 Institute of Systematics and Evolution of Animals, Polish Academy of Sciences, Sławkowska 17, 31-016 Kraków, Poland

2 Foundation for School, Densusianu Str. 6/A, 400428 Cluj-Napoca, Romania (resources), but it negatively affected hemoglobin content; however, this mostly concerned M. blythii, which had a lower parasite load. Therefore, it can be concluded that interspecific differences in ectoparasite abundance may result from parasites selecting the host species that is less sensitive to their activity. In turn, in summer ectoparasites, the preference for female hosts is probably attributable to the likelihood of reinfection rather than to an effect of host resources or health status. The absence of sex-based preferences in winter ectoparasites could be explained by equal host availability.

Keywords Hemoglobin · Hibernation · Mouse-eared bats . Parasite infection $\cdot$ Resources

\section{Introduction}

Non-random patterns of parasite abundance within a host species can be attributable to various extrinsic and intrinsic factors (Combes 2001). First, parasite infestation may depend on the host's health status (Christe et al. 2003; Reckardt and Kerth 2009), sex (Morand et al. 2004; Krasnov et al. 2012) and age (Hawlena et al. 2005). The host's susceptibility to parasitism is influenced both by its resources and the function of its immune system. Ectoparasites might choose hosts with low immunocompetence (Bize et al. 2008) or evolve strategies to avoid immunoreactions (Ribeiro 1995; Wikel 1999). Usually, the host's immune function is associated with the stored energy reserves (Corbin et al. 2008). Host species exhibiting sex differences in terms of body condition often show concurrent sex-specific differences in parasite load. According to the vulnerable host hypothesis (Christe et al. 2000), the sex with an inferior body condition may be more heavily parasitized. Conversely, the well-fed host hypothesis explains a larger parasite load in one sex as resulting from 
better nutritional resources (Christe et al. 2003; Hawlena et al. 2005). Thus, there is still no consensus as to the causal relationships between the resources of hosts, or their benefits, and the abundance of ectoparasites. The individual resources or reserves of the hosts are often correlated with hematological parameters as hematocrit or hemoglobin concentration (Thomas et al. 2007). Fluctuations in the availability of food resources may affect energy reserves and immunocompetence, and thus increase susceptibility to parasitism. In fact, periods of environmental variation and resource limitation are critical for both hosts and ectoparasites (Rueesch et al. 2012). Unfavorable conditions and periods of increased mortality or inactivity should influence the selection of an appropriate host for parasites. Thus, choosing the right host can increase the probability of ectoparasite survival, reproduction, and/or reinfection (Krasnov et al. 2005a).

Hibernation, being a unique adaptation to periodical food shortages, is widespread among insectivorous temperate-zone bat species (Speakman and Thomas 2003). Prior to hibernation, bats mate around their winter shelters (Furmankiewicz and Górniak 2002; Parsons et al. 2003) and accumulate additional fat reserves to survive the winter (Kunz et al. 1998; Kokurewicz and Speakman 2006). During hibernation, the body temperature of the bats declines to approx. $1-2{ }^{\circ} \mathrm{C}$ above the ambient temperature and their metabolic rate decreases dramatically (Geiser 2004). Bat metabolism in hibernation is reduced, with activity occurring during periodic arousals from torpor (Park et al. 2000), which account for the consumption of the majority of the stored energy (Thomas et al. 1990). Therefore, hibernation is considered a critical period in the life of bats, especially juveniles, and high winter mortality has been observed (Horáček 1985; Tuttle 1976; Speakman and Thomas 2003; but also see Ruczyński et al. 2005; Turbill et al. 2011). Resource accumulation depends to some extent on the sex and age of the host - adult females have greater fat reserves and consume them more slowly than adult males and yearlings do (Koteja et al. 2001; Jonasson and Willis 2011). With the metabolic rate reduced during hibernation, erythropoiesis and hormone levels are diminished (Kawamoto 2003). Moreover, prolonged torpor compromises immunocompetence (Burton and Reichman 1999; Moore et al. 2011; Bouma et al. 2012), while grooming activity is constrained to short episodes during arousals, which makes bats almost defenseless against parasitic infections during hibernation.

Bats are typically infected by several highly specialized blood- or lymph-feeding groups of ectoparasites which can be divided into "summer" and "winter" parasites based on the time of their breeding (Dusbábek 1972). The reproduction of the summer ectoparasites: Spinturnicidae, Nycteribiidae, and Siphonaptera are correlated with their hosts' reproduction; hence, they are most abundant during summertime and less so during the hibernation period (Hůrka 1964; Zahn and Rupp 2004; Lourenço and Palmeirim 2007). Conversely, the abundance of Macronyssidae and Ixodidae is the highest in winter, during host hibernation, and is correlated with the reproduction of parasites (Dusbábek 1972; Haitlinger 1978). The low temperature during the hibernation period should strongly reduce the food intake of the summer ectoparasites; however, they are often found to contain blood, which suggests that feeding continues through winter (Reisen et al. 1976). Ectoparasites are not very resistant to food scarcity: at a temperature of $8{ }^{\circ} \mathrm{C}$, Nycteribiidae die after 5 days without food (Hůrka 1980) and Spinturnicidae after 3 days (Deunff and Beaucournu 1981), which may also indirectly confirm the hypothesis of winter feeding.

In contrast to most mammalian hosts, where males tend to have a significantly higher parasite prevalence and intensity than females do (Morand et al. 2004; Krasnov et al. 2005b), in temperate bat species, this trend is regularly reversed (Christe et al. 2007). Sex-biased parasitism in bats is explained by the larger female resources (Christe et al. 2003) or by strategies aimed at reinfection as a result of female sociality characterizing most bat species (Zahn and Rupp 2004; Reckardt and Kerth 2009). Furthermore, physiological differences between male and female hosts may be different in reproductive and non-reproductive periods, directly leading to seasonal patterns in sex-biased parasitism (Krasnov et al. 2012). Differences in parasite infection are also seen between adult and juvenile hosts and may be the result of differences in immune resistance (Christe et al. 2000), the efficiency of ectoparasite removal during grooming (Hawlena et al. 2007), or time of ectoparasite accumulation (Hawlena et al. 2006). Finally, although bat ectoparasites tend to be host-specific, some of them can utilize a variety of hosts with varying intensity (Marshall 1982). In the case of closely related host species infected with the same ectoparasite species, even small differences in morphology, ecology, or diet can lead to different susceptibilities to a particular parasite (Freeland 1983).

In this study, we examined whether the abundance of hematophagous ectoparasites was related to the hibernation period (early and late) and host condition (body condition index and hemoglobin concentration) in different sex and age classes of the two host bat species. We investigated two sibling bat species: the greater mouse-eared bat (Myotis myotis Borkhausen, 1797) and the lesser mouse-eared bat (M. blythii Tomes, 1857), which co-occur throughout the majority of their European range (Furman et al. 2014). In Central Europe, individual members of these species are found in winter shelters from mid-November, while more bats begin to hibernate in late November and early December. For wintering, they choose large underground sites with a stable microclimate (Nagel and Nagel 1991) and often form clusters of up to several hundred individuals (Güttinger et al. 2001). In M. myotis, the hibernation season extends for 4-5 months (Wojciechowski et al. 2007), and individual torpor bouts typically last from a 3 to 20 days (Harmata 1987). In the course of 
hibernation, large mouse-eared bats lose several percent of their body weight, mainly fat reserves, with males losing more weight than females do (Koteja et al. 2001). They leave their winter shelters in mid-April, although some individuals remain underground until May. In contrast to breeding colonies, mouse-eared bats of both sexes and all ages are present in winter aggregations (Koteja et al. 2001; Gazaryan 2007).

We investigated the effects of host demography and ecology on ectoparasite abundance during winter hibernation. First, we tested the hypothesis that ectoparasite abundance differs between species as well as between host age and sex groups. The second hypothesis was that ectoparasite abundance differs between hibernation periods. According to the third hypothesis, the condition parameters such as the body condition index $(\mathrm{BCI})$ and hemoglobin concentration $(\mathrm{Hg})$ are correlated with ectoparasite abundance. One can also expect different patterns of changes in the summer and winter ectoparasites due to the differences in their biology.

\section{Materials and methods}

\section{Study area}

The study was conducted in Peştera Apă din Valea Leşului (the Water Cave in the Lesului Valley; N 46.82472; E 22.55678, altitude: 823 a.s.1); Apuseni Mts., Romania. The cave was visited twice during the hibernation period: at the beginning (December 18-21, 2010) and end (April 11-14, 2011) of the hibernation period. The microclimate of the site is stable and the temperature in the part primarily inhabited by bats during winter varied from 3.3 to $6.6{ }^{\circ} \mathrm{C}$ (with a mean of $5.2{ }^{\circ} \mathrm{C}$ ), with almost $100 \%$ relative humidity (SzodorayParádi and Szántó 1998; Fejér and Moldovan 2013). Most large mouse-eared bats hibernated approx. $80-100 \mathrm{~m}$ from the entrance in a cave segment extending for approx. 150 $200 \mathrm{~m}$, and formed clusters of up to several hundred individuals. The cave constitutes one of the largest wintering shelters of large mouse-eared bats in Romania (Nagy and Postawa 2011), and during this study, 5471 M. myotis/M. blythii individuals were found there.

\section{Bat sampling and ectoparasite collection}

Greater mouse-eared bats (Myotis myotis) and lesser mouse-eared bats (M. blythii) were collected only from mixed aggregations with more than 100 individuals per cluster. Both host species were available to a similar degree and hibernated under the same conditions. The bat species were preliminarily differentiated based on a small dark spot at the tip on the tragus (Dietz and von Helversen 2004), which is visible without disturbing the bats. After capture, bats (25-30 individuals per day) were immediately transported by car to the laboratory located about 15 min away from the cave. The animals were stored in a refrigerator at $6-8{ }^{\circ} \mathrm{C}$ and $100 \%$ humidity and were taken out immediately before ectoparasite collection and measurements. The collected bats were first identified based on upper tooth row length (L C1-M3), which is the most characteristic difference between the two studied species (Furman et al. 2014). Juveniles (first-year individuals) and adults were distinguished on the basis of fur color, the presence/absence of a black spot, and the degree of tooth wear. For each bat, forearm length (digital caliper, accuracy $0.01 \mathrm{~mm}$ ) and body mass (digital scale, accuracy $0.01 \mathrm{~g}$ ) were measured. About $50 \mu \mathrm{L}$ of blood was taken from the ventral vein of the uropatagium using a $0.3 \times 13-\mathrm{mm}$ ultrathin needle. A drop of blood was transferred by pipette to a URIT-12 hemoglobin meter strip (Hemo-Test Urit-12, Urit Medical Electronic co. LTD.), for quantitative measurement of total hemoglobin in peripheral blood $(\mathrm{g} / \mathrm{dL})$. To avoid bleeding after blood collection, cautery gel (Super Clot Gel, Synergy Labs) was applied to the puncture site to disinfect it and close the wound. In order to restore normal blood circulation, prior to blood sampling, the animals were kept for about $15 \mathrm{~min}$ at room temperature. Two parameters were applied as measures of bat condition: the body condition index (ratio of body mass to forearm length: Speakman and Racey 1986) as a proxy for the accumulated resources (Pearce et al. 2008) and hemoglobin concentration $(\mathrm{g} / \mathrm{dL})$, representing the physiological condition (Fair et al. 2007).

The fur, wing membranes, and ears were carefully examined for ectoparasites. A cotton bud with a drop of ethyl acetate was used for poisoning bat flies. Ectoparasites were collected from bats using tweezers and exhaustors and fixed in ethyl alcohol (95\%). Species were identified in the laboratory using a light microscope. Wing mites were classified following Dusbábek (1962) and Stanyukovich (1997), and bat flies were identified according to Theodor and Moscona (1954) and (Hůrka 1980). We also used a comparative collection of ectoparasites. Due to their large numbers, Macronyssidae were not determined at the species level; however, in large Myotis species, only two parasitic species may account for nearly $99 \%$ of all the arthropods found (Dusbábek 1972; Haitlinger 1978). In total, 5325 ectoparasites were collected: Spinturnix myoti Kolenati 1856 (220 individuals), Nycteribia latreillii (Leach, 1817) (82), N. vexata Westwood 1835 (372), Penicillidia dufourii (Westwood, 1835) (147), Macronyssidae (4504), Ixodidae (3), and Siphonaptera (1). A total of 217 bats, 117 M. myotis and 100 M. blythii, were examined for BCI and ectoparasites and had blood samples taken. After all measurements were made and parasites collected, the bats were released in the cave near the place where they had been collected. 
The field study was carried out under a license issued for the project LIFE08 NAT/RO/000504 by the competent Romanian authorities.

\section{Data analysis}

We used mean abundance, which is the average number of ectoparasites for a given species per individual host (Bush et al. 1997), as the parasitological parameter. Since the distribution of ectoparasite abundance is usually skewed, we used a logarithmic transformation $(\log (n+0.5))$ in ectoparasite abundance analysis. The factors potentially influencing ectoparasitic abundance were assessed using a general linear model (GLM) with a Gaussian distribution and an identity link function. Mean abundance values are reported as the mean number of ectoparasites \pm standard error (SE).

GLMs were constructed by fitting the explanatory variable: fixed factors (period of hibernation, host age, sex, and species) and covariates (the body condition index, hemoglobin concentration), which could potentially influence ectoparasite abundance. Separate GLMs were used to test speciesspecific differences in bat condition parameters and parasite load and to evaluate variation in each calculated ectoparasite abundance value, separately for the two investigated host species, three factors (host sex and age and hibernation period), and two covariates (body mass index and hemoglobin concentration).

A post hoc multiple-comparison least significance difference (LSD) test was carried out for parasite load, BCI and $\mathrm{Hg}$ between host sex/age classes for each period and species separately. The significance level used was $p<0.05$. Statistical analyses were performed using STATISTICA software version 6.0 (StatSoft Inc., Tulsa, OK, USA) and R (R Development Core Team 2011).

\section{Results}

\section{Physiological condition of the hosts}

The GLM revealed significant differences in the body condition index and hemoglobin concentration in both host species, but with distinct patterns for M. myotis and M. blythii. The body condition index of $M$. myotis was significantly higher in December than in April $(p=0.006$, Table 1), adults were heavier than juveniles were $(p<0.0001$, Table 1$)$, and a nearly significant interaction was found between period and age ( $p=0.091$, Table 1): during hibernation, BCI decreased more in adult bats than in juveniles; no significant interactions were found (Table 1). Post hoc (LSD) analysis restricted to differences between periods revealed a significant decline of $\mathrm{BCI}$ for adults: males and females (Fig. 1). In the other host species (M. blythii), the body condition index was also significantly higher in December than in April ( $p=0.0003$, Table 1) and adults were heavier than juveniles were $(p<0.0001$, Table 1$)$, but no significant interactions were found (Table 1). Post hoc (LSD) analysis of differences between periods showed a significant decline of BCI during hibernation for adult and juvenile females and for juvenile males (Fig. 1).

Hemoglobin concentration in M. myotis significantly differed only between periods, that is, in April, it was lower than in December $(p=0.003$, Table 1). No significant differences were found among other factors and their interactions (Table 1). Post hoc (LSD) analysis of differences between periods revealed a significant decline of hemoglobin in juvenile females and a nearly significant one in adult males (Fig. 1). In turn, in M. blythii, the seasonal effect was not significant, but near-significant differences were found for two interactions: between period and age (hemoglobin concentration deteriorated in juveniles, but not adults, during hibernation, $p=0.053$, Table 1 ) and between sex and age (in both sexes, adults and juveniles differed in terms of hemoglobin concentrations, $p=0.072$, Table 1). Post hoc (LSD) analysis revealed differences between December and April with a significant decline in hemoglobin concentration only in juvenile females (Fig 1).

\section{Parasites}

Host species-specific differences in ectoparasite abundance

Host species differed significantly in terms of parasite abundance (GLM: Wilk's $=0.798, F=10.8, \mathrm{df}=5.213 ; p<0.001$ ). As compared to M. blythii, M. myotis had more parasites of the following three taxa: Macronyssidae $(F=16.1, p<0.0001), S$. myoti $(F=15.7, p=0.0001)$, and $N$. vexata $(F=25.2$, $p<0.0001)$. No significant differences were found in the abundance of $P$. dufourii $(F=1.27, p=0.261)$ and $N$. latreillii $(F=0.15, p=0.70)$ (Fig. 2).

\section{Effects of demographic factors, body condition, and hibernation seasons on ectoparasite distribution}

GLM revealed only near-significant effects of two ectoparasite species, $S$. myoti $(p=0.06)$ and N. latreillii $(p=0.068)$, on the host body condition, and only for one host species $(M$. myotis). In this case, BCI tended to decrease with increasing parasitic abundance (Table 2).

In M. myotis, a significant correlation between ectoparasite abundance and hemoglobin concentration was revealed only for $N$. latreillii $(p=0.002)$, while in $M$. blythii, such a correlation was found for Macronyssidae $(p=0.026), N$. latreillii $(p=0.048)$, and $P$. dufourii $(p=0.027)$ and a nearly significant one for S. myoti ( $p=0.055)$ (Table 2). In the case of all significant correlations, hemoglobin concentration tended to decrease with increasing parasitic abundance. 
Table 1 Results of GLM analysis for the body condition index (BCI) and hemoglobin concentration (Hg) in two host species: $M$. myotis (N=100) and M. blythii $(N=117)$ as a function of period (December, April), sex (male, female), and age (juvenile, adult)

\begin{tabular}{|c|c|c|c|c|c|c|c|c|}
\hline & \multicolumn{2}{|c|}{ Myotis myotis } & \multicolumn{2}{|c|}{ Myotis blythii } & \multicolumn{2}{|c|}{ Myotis myotis } & \multicolumn{2}{|c|}{ Myotis blythii } \\
\hline & \multicolumn{4}{|c|}{ Body condition index $[\mathrm{g} / \mathrm{mm}]$} & \multicolumn{4}{|c|}{ Hemoglobin concentration $[\mathrm{g} / \mathrm{dL}]$} \\
\hline & $F$ & $p$ & $F$ & $p$ & $F$ & $p$ & $F$ & $p$ \\
\hline Intercept & 12982.8 & $<0.0001$ & 11097.0 & $<0.0001$ & 6434.0 & $<0.0001$ & 5438.6 & $<0.0001$ \\
\hline Period & 7.75 & 0.006 & 14.4 & 0.0003 & 9.08 & 0.0032 & 2.30 & 0.133 \\
\hline Sex & 0.04 & 0.84 & 1.60 & 0.208 & 0.24 & 0.624 & 0.01 & 0.946 \\
\hline Age & 17.0 & 0.0001 & 20.1 & $<0.0001$ & 0.27 & 0.607 & 1.77 & 0.186 \\
\hline Period $\times$ sex & 1.64 & 0.204 & 0.52 & 0.471 & 0.51 & 0.475 & 1.04 & 0.312 \\
\hline Period $\times$ age & 2.91 & 0.091 & 0.65 & 0.422 & 0.57 & 0.454 & 3.85 & 0.053 \\
\hline Sex $\times$ age & 0.04 & 0.848 & 0.04 & 0.833 & 0.34 & 0.560 & 3.32 & 0.072 \\
\hline Period $\times$ sex $\times$ age & 0.28 & 0.596 & 0.27 & 0.603 & 1.08 & 0.301 & 0.109 & 0.742 \\
\hline
\end{tabular}

Fig. 1 Body condition index $[\mathrm{g} / \mathrm{mm}]$ (a) and hemoglobin concentration $[\mathrm{g} / \mathrm{dL}](\mathbf{b})$ in the two host species: Myotis myotis and Myotis blythii, in sex and age classes, in early (December) and late (April) hibernation periods. Ad adult, juv juvenile. Numbers in parentheses - sample sizes. Significant differences between early and late hibernation within each sex and age classes of host species (post hoc LSD) are marked with an asterisk: * $p<0.05, * * p<0.01, * * *$ $p<0.001$
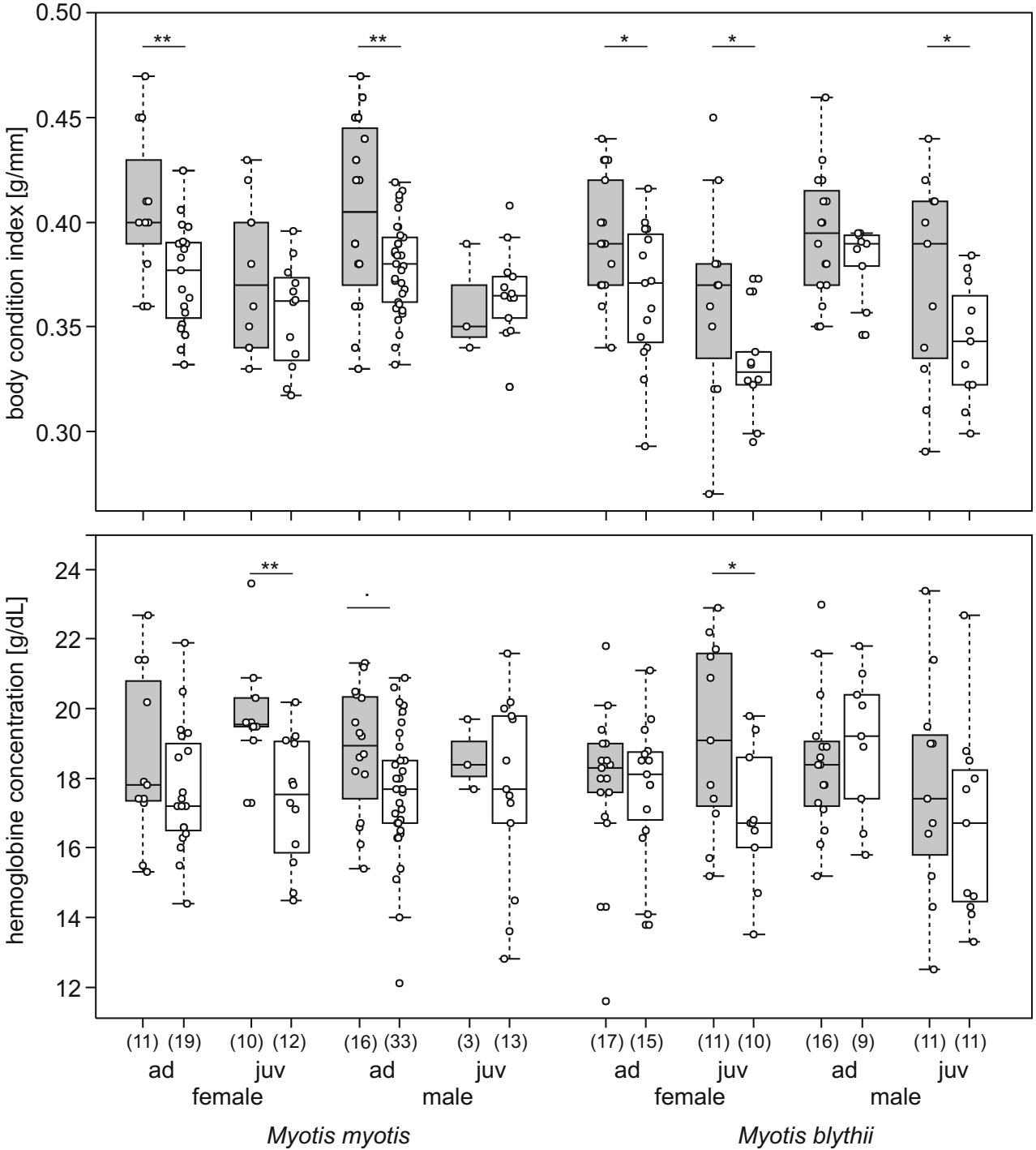
Fig. 2 Ectoparasite abundance (mean number per bat \pm SE) of a N. vexata, b P. dufourii, c N. latreillii, d S. myoti, e Macronyssidae, in sex and age classes of two host species: M. myotis and M. blythii during early-December (black bars) and late-April (white bars) hibernation period. The lines above bars indicate significant differences between classes (post hoc Tukey test): $* p<0.05$, ** $p<0.01, * * * p<0.001$
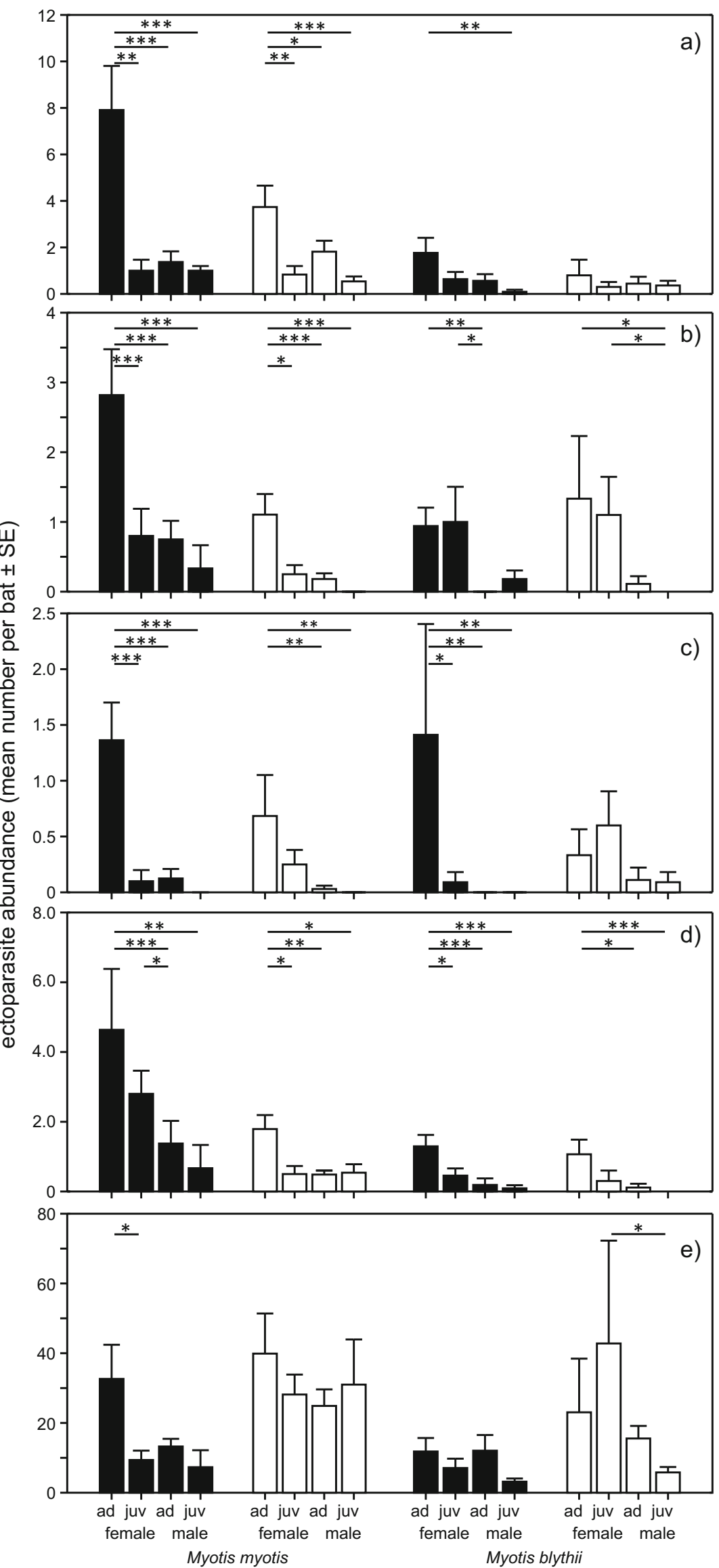
Table 2 Results of separate GLM analyses for each ectoparasite and host species

\begin{tabular}{|c|c|c|c|c|c|c|c|c|c|c|c|}
\hline \multirow[b]{2}{*}{ Myotis myotis } & \multicolumn{3}{|c|}{ Macronyssidae } & \multicolumn{2}{|c|}{ Spinturnix myoti } & \multicolumn{2}{|c|}{ Nycteribia latreillii } & \multicolumn{2}{|c|}{ Penicillidia dufourii } & \multicolumn{2}{|c|}{ Nycteribia vexata } \\
\hline & $\mathrm{df}$ & $\mathrm{F}$ & $p$ value & $\mathrm{F}$ & $p$ value & $p$ value & $p$ value & $\mathrm{F}$ & $p$ value & $\mathrm{F}$ & $p$ value \\
\hline BCI [g/mm] & 1 & 0.29 & 0.591 & 3.60 & 0.060 & 3.39 & 0.068 & 0.81 & 0.371 & 0.02 & 0.901 \\
\hline $\mathrm{Hg}[\mathrm{g} / \mathrm{dL}]$ & 1 & 0.00 & 1.000 & 1.59 & 0.210 & 10.28 & $0.002 * *$ & 0.01 & 0.940 & 0.54 & 0.465 \\
\hline Period & 1 & 5.43 & $0.022 *$ & 13.63 & $0.0004 * * *$ & 6.25 & $0.014 *$ & 12.16 & $0.001 * *$ & 2.88 & 0.092 \\
\hline Sex & 1 & 2.15 & 0.145 & 14.63 & $0.0002 * * *$ & 15.82 & $0.0001 * * *$ & 16.39 & $0.0001 * * *$ & 8.86 & $0.004 * *$ \\
\hline Age & 1 & 1.58 & 0.212 & 5.14 & $0.025^{*}$ & 10.92 & $0.001 * * *$ & 14.41 & $0.0002 * * *$ & 14.67 & $0.0001 * * *$ \\
\hline Period $\times$ sex & 1 & 0.05 & 0.816 & 5.60 & $0.020 *$ & 1.74 & 0.190 & 1.28 & 0.260 & 1.26 & 0.264 \\
\hline Period $\times$ age & 1 & 1.30 & 0.257 & 0.07 & 0.791 & 3.81 & 0.053 & 1.75 & 0.189 & 0.41 & 0.522 \\
\hline Sex $\times$ age & 1 & 0.57 & 0.451 & 1.00 & 0.319 & 4.45 & $0.037 *$ & 4.85 & $0.030^{*}$ & 8.87 & $0.004 * *$ \\
\hline Period $\times$ sex $\times$ age & 1 & 0.23 & 0.631 & 0.81 & 0.371 & 1.19 & 0.278 & 0.48 & 0.488 & 2.80 & 0.097 \\
\hline Error & 107 & & & & & & & & & & \\
\hline Myotis blythii & df & $\mathrm{F}$ & $p$ value & $\mathrm{F}$ & $p$ value & $\mathrm{F}$ & $p$ value & $\mathrm{F}$ & $p$ value & $\mathrm{F}$ & $p$ value \\
\hline Bci $[\mathrm{g} / \mathrm{mm}]$ & 1 & 0.24 & 0.625 & 0.04 & 0.841 & 0.01 & 0.935 & 0.08 & 0.781 & 0.220 & 0.640 \\
\hline $\mathrm{Hg}[\mathrm{g} / \mathrm{dL}]$ & 1 & 5.11 & $0.026^{*}$ & 3.78 & 0.055 & 4.03 & $0.048 *$ & 5.09 & $0.027 *$ & 0.464 & 0.498 \\
\hline Period & 1 & 2.87 & 0.094 & 1.48 & 0.226 & 0.03 & 0.871 & 0.11 & 0.741 & 0.603 & 0.440 \\
\hline Sex & 1 & 1.83 & 0.179 & 12.47 & $0.001 * *$ & 4.53 & $0.036^{*}$ & 14.58 & $0.0001 * * *$ & 1.964 & 0.165 \\
\hline Age & 1 & 1.14 & 0.288 & 5.39 & $0.023 *$ & 0.80 & 0.374 & 0.00 & 0.945 & 1.226 & 0.271 \\
\hline Period $\times$ sex & 1 & 0.31 & 0.576 & 0.58 & 0.448 & 0.43 & 0.513 & 0.02 & 0.888 & 1.920 & 0.169 \\
\hline Period $\times$ age & 1 & 0.17 & 0.684 & 0.20 & 0.652 & 0.84 & 0.363 & 0.38 & 0.539 & 0.562 & 0.455 \\
\hline Sex $\times$ age & 1 & 4.28 & $0.041^{*}$ & 1.73 & 0.192 & 0.05 & 0.819 & 0.13 & 0.723 & 0.080 & 0.779 \\
\hline Period $\times$ sex $\times$ age & 1 & 1.06 & 0.306 & 0.01 & 0.912 & 1.86 & 0.176 & 0.27 & 0.602 & 0.004 & 0.948 \\
\hline Error & 90 & & & & & & & & & & \\
\hline
\end{tabular}

Period: December, April; sex: male, female; age: juvenile, adult

$B C I$ body condition index, $\mathrm{Hg}$ hemoglobin concentration

Significant differences are marked with an asterisk: $* p<0.05 ; * * p<0.01 ; * * * p<0.001$

The hibernation period affected the abundance of four investigated ectoparasite taxa parasitizing M. myotis: Macronyssidae were more numerous in April $(p=0.022)$, while the remaining species in December $(p=0.0004$ for S. myoti, $p=0.014$ for N. latreillii, and $p=0.0007$ for P. dufourii). No effect was found for M. blythii. M. myotis females were more heavily parasitized by all summer ectoparasite species: S. myoti $(p=0.0002)$, N. latreillii $(p=0.0001)$, $N$. vexata $(p=0.004)$, and $P$. dufourii $(p=0.0001)$, but not by Macronyssidae $(p=0.145)$, in which case both host sexes were parasitized to a comparable degree. A similar pattern was observed in M. blythii with one exception; no differences were found in $N$. vexata.

Host age affected the abundance of all summer ectoparasite species in M. myotis: adult hosts were more heavily parasitized than were juveniles by $S$. myoti $(p=0.025), N$. latreillii $(p=0.0013), P$. dufourii $(p=0.0002)$, and $N$. vexata $(p=0.0002)$. In turn, in the case of M. blythii, significantly more ectoparasites on adult bats were found only for $S$. myoti $(p=0.023)$.

A significant two-way interaction between hibernation period and sex was found for S. myoti $(p=0.020)$, and a near- significant one for $N$. latreillii, parasitizing $M$. myotis $(p=0.053)$. The interaction between sex and age was significant for all Nycteribiidae species, which parasitized M. myotis: $N$. latreillii $(p=0.037), P$. dufourii $(p=0.03)$, and $N$. vexata $(p=0.004)$, but only for Macronyssidae $(p=0.041)$ in $M$. blythii. No significant three-way interactions were identified.

\section{Discussion}

\section{Host species-specific patterns in ectoparasite abundance and body condition}

Although the investigated host species were similar in body size (Arlettaz 1995), thermoregulatory behavior (Schuller et al. 2010), and geographical range and shared both breeding and hibernation shelters (Güttinger et al. 2001), they differed in terms of parasite load. Among the studied summer and winter ectoparasite species, three were more abundant on $M$. myotis than on M. blythii. Another two species, P. dufourii and N. latreillii, which were equally numerous on 
both bat species, exhibited host species-specific patterns of abundance. Species-specific differences are known primarily from the breeding period: in mixed maternity colonies, M. myotis are reported to be significantly more heavily infected by the wing mite $S$. myoti than M. blythii (Christe et al. 2003). The other ectoparasite species which often parasitize large Myotis species are known almost exclusively from single-species summer colonies of either M. myotis (Hůrka 1964; Zahn and Rupp 2004) or M. blythii (Sharifi et al. 2008); hence, in those cases, interspecific differences in parasite abundance remain undetermined. Closely related hosts, such as sibling or sister species, are typically infected by the same ectoparasite species (Mouillot et al. 2006), but they can differ in their abundance (Freeland 1983). Differences may originate mainly from the capacity of the host to deter and/or resist the parasites (Christe et al. 2003; Thomas et al. 2000), or to some extent, from host abundance (Mlynarek et al. 2012; Stanko et al. 2002). Since the two bat species form mixed aggregations during both breeding and wintering (Güttinger et al. 2001), the influence of host availability on parasite abundance is unlikely. While starved or energy-deprived hosts may be less resistant to parasites (Valera et al. 2004; Krasnov et al. 2005a; Hawlena et al. 2005), hosts in good condition can be a better source or nourishment (Christe et al. 2003; Rueesch et al. 2012). If the host's resources were predictive of ectoparasite abundance, interspecific differences in body condition could explain the differences, but our results do not support this hypothesis. The deterioration of host body condition during hibernation differed to some extent between the host species, but the underlying causes were of intraspecific rather than interspecific nature. During natural hibernation, some bats can actively control their energy balance, primarily by winter feeding (Ransome 1990). This applies almost exclusively to bat species with a gleaning foraging strategy, whose prey (Diptera, Lepidoptera) may be active during warmer days in the winter (Park et al. 2000; Hope et al. 2014). Therefore, differences in the pattern of BCI decline between sex-age host groups can be attributable to the availability of active insects during wintering, as well as to mating behavior; however, this issue is not clear and requires further study.

The preference for one host species both of summer and winter ectoparasites suggests that they have similar mechanisms for selecting an optimum host species. While blood may contain chemical signals useful for identifying the appropriate host species by ectoparasites (Christe et al. 2000; Klein 2005), during hibernation, endocrine secretion is strongly reduced, hormone levels in the blood are marginal (Kawamoto 2003), and the immune function is depressed (Burton and Reichman 1999; Bouma et al. 2012). Alternatively, a species-specific odor-profile may be used by ectoparasites for host selection (Lourenço and Palmeirim 2008; Chaisson and Hallem 2012). The diet of M. myotis mainly consists of Carabidae, whose abdominal defensive glands secrete esters
(Lečić et al. 2014), while the diet of M. blythii is almost exclusively limited to Orthoptera, which do not have chemical defenses, and the resulting differences in odor between the two bat species are strong enough to be noted by humans (indeed, they were observed by the researchers conducting this study). Finally, despite the fact that M. myotis was parasitized much more heavily than $M$. blythii was, no parasitedependent differences in body condition or its decline during hibernation were identified.

The other parameter of body condition, hemoglobin concentration, was slightly lower at the end of hibernation, with the most significant decrease found in first-year females in both host species, but without a species-specific pattern. Despite diminished erythropoiesis during hibernation, bats were characterized by a rather constant level of hemoglobin concentration throughout the year (Grundboeck and Krzanowski 1957; Wołk and Ruprecht 1988). This lack of apparent differences is probably attributable to the storage of red blood cells in the spleen, which is twice as large in inactive animals as in flying ones (Krutzsch and Hughes 1958; Jürgens et al. 1981; Neuweiler 2000). In mammals, hematological parameters such as hemoglobin concentration and hematocrit depend to some extent on sex and age: adult males exhibit higher values than females do, while in juveniles, sex differences are not found (Sealander 1964; Murphy 2014). In turn, juveniles are more sensitive to blood loss than adults are (Hawlena et al. 2007). In this study, first-year females of both host species were more parasitized than males were by the summer ectoparasites, including nycteribiids and wing mites, which are not resistant to starvation (Hůrka 1980; Deunff and Beaucournu 1981), and also feed during winter, but not as frequently as during the summer activity of the host. Therefore, the volume of host blood obtained by these ectoparasites should be higher in females than in males, and in conjunction with reduced hematopoiesis during hibernation, may explain the differences in hemoglobin concentration between first-year males and females.

\section{Intraspecific factors affect ectoparasite abundance}

The body condition parameters of the hosts are correlated with ectoparasite abundance in different ways. We found no clear evidence for ectoparasite load to reduce body condition. Ectoparasites feed mainly on blood and lymph and do not directly use the fat resources of the hosts, and so they have no directional impact on BCI. During hibernation, fat resources are mainly affected by arousals, which constitute the main cost of hibernation (Speakman and Thomas 2003). No significant effect of sex (Park et al. 2000), or even age and $\mathrm{BCI}$, on the frequency of arousals or bouts of torpor has been observed (Jonasson and Willis 2012). Then, the only way in which ectoparasites could influence BCI would be by increasing arousal frequency, which is unlikely. In turn, in this study, 
hemoglobin concentration was sensitive to ectoparasite abundance and decreased with increasing parasite load, with the only exception being $N$. vexata. A directional impact of ectoparasites on the host's blood parameters is rarely found (Christe et al. 2000; Hawlena et al. 2006), probably as a result of the rapid production of new cells in response to blood loss (regenerative anemia, Pfäffle et al. 2009); however, it has been observed for hemoglobin concentration (O'Brien et al. 2001; Carleton 2008). Despite the lower abundance of parasites in M. blythii, this species exhibited a greater hemoglobin decline and for a greater number of ectoparasite species than in the case of M. myotis. These results demonstrate not only an ectoparasite-specific effect on the host, but also one that is independent of the mode of parasite transmission. It can be inferred that ectoparasites prefer hosts which are less sensitive to their direct impact (blood intake), but with independence from the host's resources allowed survival of temporary food shortage.

During hibernation, the abundance of almost all summer ectoparasites decreased while that of Macronyssidae increased; however, this difference was found only for one host (M. myotis). The lack of a significant difference in M. blythii may have resulted from a lower load and larger abundance variation of ectoparasites. The summer ectoparasite species feed on blood and they are not entirely deprived of food during hibernation, but its availability can be limited to short episodes during host arousals. In M. myotis, torpor bouts last from a 3 to 20 days (Harmata 1987) throughout the hibernation season, which lasts 4-5 months (Wojciechowski et al. 2007) during which up to several dozen arousals occur. Therefore, arousals allow ectoparasites to survive winter, but hibernation contributes to some extent to reducing their abundance. The seasonal changes in ectoparasite abundance were somewhat influenced by host sex and age, but only in the case of $M$. myotis. The abundance of $S$. myoti was found to decrease in females, while in males, it remained at the same level. In turn, in N. latreilli, a larger decrease in abundance occurred in adults, while in juveniles, it remained unchanged. The fact that in both cases ectoparasite abundance declined in the sex and age host categories characterized by better body condition may indicate a potential trade-off between the choice of a better host and its stronger defenses. However, the ways in which hosts could bring about reduced ectoparasite abundance during a period of inactivity requires further research. In turn, Macronyssidae can not only feed during hibernation but also reproduce (Dusbábek 1972, Haitlinger 1978), and hence their abundance is higher at the end of hibernation.

The host sex-biased preferences of ectoparasites reproducing in the summer (nycteribiids and wing mites) were distinct from those found in Macronyssidae, which mostly reproduce in the winter. The higher summer parasite abundance in female adult hosts at the beginning of hibernation may result from their larger resources, suggesting a better quality or more profitable host (Christe et al. 2007), and also from other factors, such as age and the resulting greater number of opportunities to encounter parasites (Tinsley 1989; Hawlena et al. 2006). In contrast to previous results (Christe et al. 2007), at the beginning of hibernation, we found sex-biased ectoparasite preferences also among first-year old bats: females were more heavily infected than males were. During the reproduction of summer ectoparasite species, host aggregations (breeding colonies) initially consist almost exclusively of adult females, and later on also of their offspring. Therefore, the possibility of reinfection seems to be a major factor in the female bias of most summer bat ectoparasites. Transfer to the host breeding colony, where ectoparasites also reproduce, is possible almost only by females (whether juvenile or adult) (Webber et al. 2015). In turn, at the end of the hibernation period, there was no apparent difference in the abundance of Macronyssidae between hosts of different sexes and ages. The lack of sex-biased preferences in winter-reproducing ectoparasites is again linked to host availability and may result from the fact that in the wintering site, all sex-age host groups were equally accessible. These results lead to the conclusion that the possibility of reinfection in conjunction with host availability can promote sex-biased parasite infestation in bats.

However, in some cases, sex bias depended on the age of the host. While both male and female juvenile bats were parasitized to a comparable degree, the host sex preferences of ectoparasites differed for adult bats, but only in the case of Nycteribiidae parasitizing M. myotis and Macronyssidae parasitizing M. blythii. Newborn hosts are more heavily parasitized than adult females aew, but throughout the nursery period, parasite abundance decreases (Encarnação et al. 2012; Christe et al. 2000). These changes can be the effect of acquiring the ability to groom (Giorgi et al. 2001); however, grooming efficiency depends on ectoparasite microhabitat specialization (naked vs. haired skin) (Godinho et al. 2013). Therefore, the lower ectoparasite abundance in juvenile bats is rather caused by the time to encountering parasites than by grooming or an immunocompetence effect (Tinsley 1989; Hawlena et al. 2006).

In conclusion, we found no species-specific patterns in terms of deteriorating host body condition or decreasing hemoglobin concentration during hibernation, despite the differences in the abundance of both summer and winter ectoparasites. While hemoglobin concentration showed a similar pattern, we noted unusual most decreasing in juvenile females in both of host's species. Since first-year female hosts were more heavily parasitized than males were, it is possible that a significant decrease in hemoglobin content was due to a larger volume of food (blood) consumed by the parasites. However, this does not apply to adult bats.

In turn, at the intraspecific level, ectoparasite abundance had a significant effect on hemoglobin content, but this 
applied almost exclusively to one host species, M. blythii, despite its lower parasite load. On the other hand, body condition was not affected by ectoparasite abundance. This indicates that ectoparasites preferred hosts, which were less sensitive to their activity but did not show a bias for host resources. A better health status may have been preferred due to a higher likelihood of survival until the spring migration. Finally, female-biased parasitism in summer ectoparasite species seems to constitute a strategy that facilitates reinfection in the maternity colony of the host rather than prioritize female resources or survival likelihood. This is consistent with the absence of host sex preferences in winter ectoparasites, as in that case where both host sexes are equally available during the breeding of parasites.

Acknowledgments We are grateful to Szilard Bucs (the Romanian Bat Protection Association, Satu Mare), Maurycy Ignaczak (the Polish Society for Nature Protection "Salamandra"), Jarosław Manias (the Polish Society for Bat Protection), and Justyna Bachanek (the Institute of Systematics and Evolution of Animals PAS, Krakow) for their assistance in material collection during fieldwork.

Open Access This article is distributed under the terms of the Creative Commons Attribution 4.0 International License (http:// creativecommons.org/licenses/by/4.0/), which permits unrestricted use, distribution, and reproduction in any medium, provided you give appropriate credit to the original author(s) and the source, provide a link to the Creative Commons license, and indicate if changes were made.

\section{References}

Arlettaz R (1995) Ecology of the sibling mouse-eared bats (Myotis myotis and Myotis blythii): zoogeography, niche, competition, and foraging. Horus Publishers Martigny, Valais, $208 \mathrm{pp}$

Bize P, Devevey G, Monaghan P, Doligez B, Christe P (2008) Fecundity and survival in relation to resistance to oxidative stress in a freeliving bird. Ecology 89(9):2584-2593

Bouma HR, Strijstra AM, Talaei F, Henning RH, Carey HV, Kroese GM (2012) The hibernation immune system. [in] Ruf et al. (eds.), Living in a season world. Springer-Verlag: 259-270

Burton RS, Reichman OJ (1999) Does immune challenge affect torpor duration? Funct Ecol 13:232-237

Bush AO, Lafferty KD, Lotz JF, Shostak AC (1997) Parasitology meets ecology on its own terms: Margolis et al. revisited. J Parasitol 83: $575-583$

Carleton RE (2008) Ectoparasites affect hemoglobin and percentages of immature erythrocytes but not hematocrit in nestling Eastern Bluebirds. Wilson J Ornithol 120:565-568

Chaisson KE, Hallem EA (2012) Chemosensory behaviors of parasites. Trends Parasitol 28(10):427-438

Christe P, Arlettaz R, Vogel P (2000) Variation in intensity of a parasitic mite (Spinturnix myoti) in relation to the reproductive cycle and immunocompetence of its bat host (Myotis myotis). Ecol Lett 3: 207-212

Christe P, Giorgi MS, Vogel P, Arlettaz R (2003) Differential speciesspecific ectoparasitic mite intensities in two intimately coexisting sibling bat species: resource-mediated host attractiveness or parasite specialization? J Anim Ecol 72:866-872

Christe P, Glaizot O, Evanno G, Bruyndonckx N, Devevey G, Yannic G, Patthey P, Maeder A, Vogel P, Arlettaz R (2007) Host sex and ectoparasites choice: preference for, and higher survival on female hosts. J Anim Ecol 76:703-710

Combes C (2001) Parasitism. The ecology and evolution of intimate interactions. University of Chicago Press, Chicago, p 699

Corbin E, Vicente J, Martin-Hernando MP, Acevedo P, Pérez-Rodríguez L, Gortazar C (2008) Spleen mass as a measure of immune strength in mammals. Mamm Rev 38:108-115

Deunff J, Beaucournu J-C (1981) Phenologie et variations du dermecos chez quelques especes de Spinturnicidae (Acarina, Mesostigmata). Ann Parasitol Hum Comp 56:203-224

Dietz C, von Helversen O (2004) Illustrated identification key to the bats of Europe, Tuebingen \& Erlangen. Electronic publication. Available at: http://biocenosi.dipbf.uninsubriait/didattica/bat key2.pdf

Dusbábek F (1962) Parasitische Fledermausmilben der Tschechoslowakei I. Fam. Spinturnicidae Oudms., 1901 (Acarina, Gamasides). Acta Soc Entomol Cechoslov 59:357-380

Dusbábek F (1972) The zone of bat acarinia in central Europe. Folia Parasitol 19:139-154

Encarnação JA, Baulechner D, Becker NI (2012) Seasonal variations of wing mite infestations in male Daubenton's bats (Myotis daubentonii) in comparison to female and juvenile bats. Acta Chiropterol 14:153-159

Fair J, Whitaker S, Pearson B (2007) Sources of variation in haematocrit in birds. Ibis 149:535-552

Fejér A, Moldovan OT (2013) Population size and dispersal patterns for a Drimeotus (Coleoptera, Leiodidae, Leptodirini) cave population. Subterr Biol 11:31-44

Freeland WJ (1983) Parasites and the coexistence of animal host species. Am Nat 121:223-236

Furman A, Coraman E, Celik YE, Postawa T, Bachanek J, Ruedi M (2014) Cytonuclear discordance and the species status of Myotis myotis and Myotis blythii (Chiroptera). Zool Scr 43:549-561

Furmankiewicz J, Górniak J (2002) Seasonal changes in number and diversity of bat species (Chiroptera) in the Stolec mine (SW Poland). Przyroda Sudetow Zachodnich 2:49-70

Gazaryan SV (2007) Sex ratio and age structure in the population of lesser mouse-eared bat Myotis blythii in Northern Caucasus. [in] Prigioni C, Sforzi A (eds) 2007. Abstracts V European Congress of Mammalogy, Hystrix It J Mamm (n.s.) Vol. I-2, Supp. (2007):206

Geiser F (2004) Metabolic rate and body temperature reduction during hibernation and daily torpor. Annu Rev Physiol 66:239-274

Giorgi MS, Arlettaz R, Christe P, Vogel P (2001) The energetic grooming costs imposed by a parasitic mite (Spinturnix myoti) upon its bat host (Myotis myotis). Proc R Soc B 268:2071-2075

Godinho LN, Cripps JK, Coulson G, Lumsden LF (2013) The effect of ectoparasites on the grooming behaviour of Gould's wattled bat (Chalinolobus gouldii): an experimental study. Acta Chiropt 15: 463-472

Grundboeck M, Krzanowski A (1957) Morphological investigations on the blood of some European species of bats. Zool Pol 8:349-368

Güttinger R, Zahn A, Krapp F, Schober W (2001) Myotis myotis (Borkhausen, 1797) - Großes Mausohr, Großmausohr. In: F. Krapp (ed.), Handbuch der Säugetiere Europas. Band 4: Fledertiere. Teil I: Chiroptera I. Rhinolophidae, Vespertilionidae 1, 123-207. AulaVerlag, Wiebelsheim, Germany

Haitlinger R (1978) External parasites of the Lower Silesian bats. V. Macronyssidae, Dermanyssidae, Veigaiaidae. Wiad Parazytol 24: $707-716$

Harmata W (1987) The frequency of winter sleep interruptions in two species of bats hibernating in limestone tunnels. Acta Theriol 32: 331-332

Hawlena H, Abramsky Z, Krasnov BR (2005) Age-biased parasitism and density-dependent distribution of fleas (Siphonaptera) on a desert rodent. Oecologia 146:200-208

Hawlena H, Abramsky Z, Krasnov BR (2006) Ectoparasites and agedependent survival in a desert rodent. Oecologia 148:30-39 
Hawlena H, Abramsky Z, Krasnov BR (2007) Ultimate mechanisms of age-biased flea parasitism. Oecologia 154:601-609

Hope PR, Bohmann K, Gilbert MTP, Zepeda-Mendoza ML, Razgour O, Jones G (2014) Second generation sequencing and morphological faecal analysis reveal unexpected foraging behaviour by Myotis nattereri (Chiroptera, Vespertilionidae) in winter. Front Zool 11:39

Horáček I (1985) Population ecology of Myotis myotis in central Bohemia (Mammalia: Chiroptera). Acta Univ Carol Biol 8:161-267

Hůrka K (1964) Distribution, bionomy and ecology of the European bat flies with species regard to the Czechoslovak fauna (Dipt., Nycteribiidae). Acta Univ Carol Biol 3:167-234

Hůrka K (1980) Nycteribiidae - Muchulovití. Pp.: 479-509. In: Chvála M. (ed.): Krevsající mouchy a strečci - Diptera. Čeledi Ceratopogonidae, Simuliidae, Tabanidae, Hypodematidae, Oestridae, Gasterophilidae, Hippoboscidae a Nycteribiidae. Fauna ČSSR, svazek 22. Academia, Praha, 540 pp.

Jonasson KA, Willis CKR (2011) Changes in body condition of hibernating bats support the thrifty female hypothesis and predict consequences for populations with white-nose syndrome. PLoS ONE 6(6), e21061

Jonasson KA, Willis CKR (2012) Hibernation energetics of free-ranging little brown bats. J Exp Biol 215:2141-2149

Jürgens JD, Bartels H, Bartels R (1981) Blood oxygen transport and organ weight of small bats and small non-flying mammals. Respir Physiol 45:243-260

Kawamoto K (2003) Endocrine control of the reproductive activity in hibernating bats. Zool Sci 20:1057-1069

Klein SL (2005) Hormonal and immunological mechanisms mediating sex differences in parasite infection. Parasite Immunol 26:247-264

Kokurewicz T, Speakman JR (2006) Age related variation in the energy costs of torpor in Daubenton's bat: effects on fat accumulation prior to hibernation. Acta Chiropterol 8(2):509-521

Koteja P, Jurczyszyn M, Wołoszyn BW (2001) Energy balance of hibernating mouse-eared bat Myotis myotis: a study with TOBEC instrument. Acta Theriol 46:1-12

Krasnov BR, Khokhlova IS, Arakelyan MS, Degen AA (2005a) Is a starving host tastier? Reproduction in fleas parasitizing food limited rodents. Funct Ecol 19:625-631

Krasnov BR, Morand S, Hawlena H, Khokhlova IS, Shenbrot G (2005b) Sex-biased parasitism, seasonality and sexual size dimorphism in desert rodents. Oecologia 146:209-217

Krasnov BR, Bordes F, Khokhlova IS, Morand S (2012) Gender-biased parasitism in small mammals: patterns, mechanisms, consequences. Mammalia 76:1-13

Krutzsch PH, Hughes AH (1958) Hematological changes with torpor in the bats. J Mammal 40:547-554

Kunz TH, Wrazen JA, Burnett CD (1998) Changes in body mass and fat reserves in pre-hibernating little brown bats (Myotis lucifugus). Ecoscience 5:8-17

Lečić S, Ćurčić S, Vujisić L, Ćurčić B, Ćurčić N, Nikolić Z, Anđelković B, Milosavljević S, Tešević V, Makarov S (2014) Defensive secretions in three ground-beetle species (Insecta: Coleoptera: Carabidae). Ann Zool Fenn 51(3):285-300

Lourenço S, Palmeirim J (2007) Can mite parasitism affect the condition of bat hosts? Implications for the social structure of colonial bats. J Zool 273:161-168

Lourenço S, Palmeirim J (2008) How do ectoparasitic nycteribiids locate their bat hosts? Parasitol 135:1205-1213

Marshall AG (1982) Ecology of insects ectoparasitic on bats. In: Kunz TH (ed) Ecology of Bats. Plenum, New York, pp 369-401

Mlynarek JJ, Hassall C, Forbes MR (2012) Higher gregarine parasitism often in sibling species of host damselflies with smaller geographical distributions. Ecol Entomol 37:419-425

Moore MS, Reichard JD, Murtha TD, Zahedi B, Fallier RM, Kunz TH (2011) Specific alterations in complement protein activity of little brown myotis (Myotis lucifugus) hibernating in whitenose syndrome affected sites. PLoS ONE 6:e27430

Morand S, Gouy de Bellocq J, Stanko M, Miklisova D (2004) Is sex biased ectoparasitism related to sexual size dimorphism in small mammals of Central Europe? Parasitology 129:505-510

Mouillot D, Krasnov BR, Shenbrot GI, Gaston KJ, Poulin R (2006) Conservatism of host specificity in parasites. Ecography 29:596602

Murphy WG (2014) The sex difference in haemoglobin levels in adultsmechanisms, causes, and consequences. Blood Rev 28(2):41-47

Nagel A, Nagel R (1991) How do bats choose optimal temperatures for hibernation? Comp Biochem Physiol 99A:323-326

Nagy Z, Postawa T (2011) Seasonal and geographical distribution of cave dwelling bats in Romania-implications for conservation. Anim Conserv 14:74-86

Neuweiler G (2000) The blood. In: Neuweiler G (ed) The biology of bats. Oxford University Press, Oxford, pp 53-55

O'Brien EL, Morrison BL, Johnson LS (2001) Assessing the effects of haematophagous ectoparasites on the health of nestling birds: haematocrit vs haemoglobin levels in House Wrens parasitized by blow fly larvae. J Avian Biol 32:73-76

Park KJ, Jones G, Ransome RD (2000) Torpor, arousal and activity of hibernating Greater Horseshoe Bats (Rhinolophus ferrumequinum). Funct Ecol 14:580-588

Parsons KN, Jones G, Greenaway F (2003) Swarming activity of temperate zone microchiropteran bats: effects of season, time of night and weather conditions. J Zool 261:257-264

Pearce RD, O'Shea TJ, Wunder BA (2008) Evaluation of morphological indices and total body electrical conductivity to assess body composition in big brown bats. Acta Chiroprol 10:153-159

Pfäffle M, Petney T, Elgas M, Skuballa J, Taraschewski H (2009) Tickinduced blood loss leads to regenerative anaemia in the European hedgehog (Erinaceus europaeus). Parasitology 136:443-452

Ransome R (1990) Hibernating bats. Christopher Helm, London, 235 pp

Reckardt K, Kerth G (2009) Does the mode of transmission between hosts affect the host choice strategies of parasites? Implications from a field study on bat fly and wing mite infestation of Bechstein's bats. Oikos 118:183-190

Reisen WK, Kennedy ML, Reisen NT (1976) Winter ecology of ectoparasites collected from hibernating Myotis velifer (Allen) in southwestern Oklahoma (Chiroptera: Vespertilionidae). J Parasitol 62:628638

Ribeiro JMC (1995) Blood-feeding arthropods: live syringes or invertebrate pharmacologists. Infect Agents Dis 4:143-152

Ruczyński I, Ruczyńska I, Kasprzyk K (2005) Winter mortality rates of bats inhabiting man-made shelters (northern Poland). Acta Theriol 50:161-166

Rueesch S, Lemoine M, Richner M (2012) Ectoparasite reproductive performance when host condition varies. Parasitol Res 111:11931203

Schuller B-M, Voigt CC, Dausmann KH, Siemers BM (2010) Do thermoregulatory behaviour and related costs reflect differences in geographic distribution between closely related bats, Myotis myotis and M. blythii oxygnathus, in Europe? [in:] Ivan Horáček and Petr Benda. Programme, abstracts, list of participants. Volume of abstracts of the 15th International Bat Research Conference, held in Prague, 23-27 August 2010 280-281. 380 pp

Sealander JA (1964) The influence of body size, season, sex, age and other factors upon some blood parameters in small mammals. J Mammal 45:598-616

Sharifi M, Mozafari F, Taghinezhad N, Javanbakht H (2008) Variation in ectoparasite load reflects life history traits in the lesser mouse-eared bat Myotis blythii (Chiroptera: Vespertilionidae) in Western Iran. J Parasitol 94:622-625 
Speakman JR, Racey PA (1986) The influence of body condition on sexual development of male brown long-eared bats (Plecotus auritus) in the wild. J Zool 210:515-525

Speakman JR, Thomas DW (2003) Physiological ecology and energetics of bats. In: Kunz TH, Fenton MB (eds) Bat Ecology. The University of Chicago Press, Chicago, pp 430-490

Stanko M, Miklisova D, Gouy De Bellocq J, Morand S (2002) Mammal density and patterns of ectoparasite species richness and abundance. Oecologia 131:289-295

Stanyukovich MK (1997) Keys to the gamasid mites (Acari, Parasitiformes, Mesostigmata, Macronyssoidea and Laelaptoidea) parasitizing bats (Mammalia, Chiroptera) from Russia and adjacent countries. Rudolstädter Naturhistorische Schriften 7:13-46

Szodoray-Parádi F, Szántó L (1998) Telelési sajátosságok a közönséges egérfülü denevérnél (Myotis myotis) és nagy patkósorrú denevérnél (Rhinolophus ferrumequinum) a Csarnóházi és a Les-völgyi vizesbarlangokban. Collegium Biologicum 1:55-59

Theodor O, Moscona A (1954) On bat parasites in Palestine. I. Nycteribiidae, Streblidae, Hempitera, Siphonaptera. Parasitology 44:157-245

Thomas DW, Dorais M, Bergeron JM (1990) Winter energy budgets and cost of arousals for hibernating little brown bats, Myotis lucifugus. J Mammal 71:475-479

Thomas F, Guégan J-F, Michalakis Y, Renaud F (2000) Parasites and host life-history traits: implications for community ecology and species co-existence. Int J Parasitol 30:669-674

Thomas DW, Shipley B, Blondel J, Perret P, Simon A, Lambrechts MM (2007) Common paths link food abundance and ectoparasite loads to physiological performance and recruitment in nestling blue tits. Funct Ecol 21:947-955

Tinsley RC (1989) The effects of host sex on transmission success. Parasitol Today 5:190-195

Turbill C, Bieber C, Ruf T (2011) Hibernation is associated with increased survival and the evolution of slow life histories among mammals. Proc R Soc B 278:3355-3363

Tuttle MD (1976) Population ecology of the gray bat (Myotis grisescens): factors influencing growth and survival of newly volant young. Ecology 57:587-595

Valera F, Hoi H, Darolová A, Krištofík J (2004) Size vs. health as a cue for host choice: a test of the tasty chick hypothesis. Parasitology 129: 59-68

Webber QMR, McGuire LP, Smith SB, Willis CKR (2015) Host behaviour, age and sex correlate with ectoparasite prevalence and intensity in a colonial mammal, the little brown bat. Behaviour 152:83-105

Wikel SK (1999) Modulation of the host immune system by ectoparasitic arthropods. Bioscience 49:311-320

Wojciechowski MS, Jefimow M, Tegowska E (2007) Environmental conditions, rather than season, determine torpor use and temperature selection in large mouse-eared bats (Myotis myotis). Comp Biochem Phys A 147:828-840

Wołk E, Ruprecht AL (1988) Haematological values in the serotine bat, Eptesicus serotinus (Schreber, 1774). Acta Theriol 33:545-553

Zahn A, Rupp D (2004) Ectoparasite load in European vespertilionid bats. J Zool 262:1-9 